\title{
Antagonism of PACAP or Microglia Function Worsens the Cardiovascular Consequences of Kainic-Acid-Induced Seizures in Rats
}

\author{
(DAmol M. Bhandare, ${ }^{1,2}$ Suja Mohammed, ${ }^{2}$ Paul M. Pilowsky, ${ }^{2,3}$ and Melissa M.J. Farnham ${ }^{1,2}$ \\ ${ }^{1}$ Australian School of Advanced Medicine, Macquarie University, Sydney, 2109 New South Wales, Australia, ${ }^{2}$ The Heart Research Institute, 2042 New South \\ Wales, Australia, and ${ }^{3}$ Department of Physiology, University of Sydney, Sydney, 2006 New South Wales, Australia
}

\begin{abstract}
Seizures are accompanied by cardiovascular changes that are a major cause of sudden unexpected death in epilepsy (SUDEP). Seizures activate inflammatory responses in the cardiovascular nuclei of the medulla oblongata and increase neuronal excitability. Pituitary adenylate cyclase-activating polypeptide (PACAP) is a neuropeptide with autocrine and paracrine neuroprotective properties. Microglia are key players in inflammatory responses in the CNS. We sought to determine whether PACAP and microglia mitigate the adverse effects of seizure on cardiovascular function in a rat model of temporal lobe epilepsy. Kainic acid (KA)-induced seizures increased splanchnic sympathetic nerve activity by $97 \%$, accompanied by increase in heart rate (HR) but not blood pressure (BP). Intrathecal infusion of the PACAP antagonist PACAP $(6-38)$ or the microglia antagonists minocycline and doxycycline augmented sympathetic responses to KAinduced seizures. PACAP(6-38) caused a $161 \%$ increase, whereas minocycline and doxycycline caused a $225 \%$ and $215 \%$ increase, respectively. In intrathecal PACAP-antagonist-treated rats, both BP and HR increased, whereas after treatment with microglial antagonists, only BP was significantly increased compared with control. Our findings support the idea that PACAP and its action on microglia at the level of the spinal cord elicit cardioprotective effects during seizure. However, intrathecal PACAP did not show additive effects, suggesting that the agonist effect was at maximum. The protective effect of microglia may occur by adoption of an M2 phenotype and expression of factors such as TGF- $\beta$ and IL-10 that promote neuronal quiescence. In summary, therapeutic interventions targeting PACAP and microglia could be a promising strategy for preventing SUDEP.
\end{abstract}

Key words: kainic acid; microglia; PACAP; seizure; SUDEP; sympathetic nerve activity

\section{Introduction}

Epileptic seizures are commonly accompanied by autonomic changes that include disturbances in blood pressure (BP), heart rate (HR), and heart rhythm (Wannamaker, 1985; Darbin et al., 2002; Müngen et al., 2010; Pansani et al., 2011). These cardiovascular changes may be dramatic and lead to "sudden unexpected death in epilepsy" (SUDEP), a syndrome that accounts for $5-17 \%$ of deaths in people with epilepsy (Sakamoto et al., 2008; Brotherstone et al., 2010; Tolstykh and Cavazos, 2013).

Pituitary adenylate cyclase-activating polypeptide (PACAP) is a 38 aa peptide that activates three receptors: PAC1R, VPAC1R, and VPAC2R. The canonical pathway in each case is activation of

Received Sept. 30, 2014; revised Dec. 18, 2014; accepted Dec. 23, 2014.

Author contributions: A.M.B., P.M.P., and M.M.J.F. designed research; A.M.B., S.M., and M.M.J.F. performed research; A.M.B., S.M., P.M.P., and M.M.J.F. contributed unpublished reagents/analytic tools; A.M.B., P.M.P., and M.M.J.F. analyzed data; A.M.B., P.M.P., and M.M.J.F. wrote the paper.

This work was supported by the Australian Research Council (Discovery Early Career Researcher Award DE120100992), the National Health and Medical Research Council of Australia (Grant 1065485 and Fellowship 1024489), and the Heart Research Institute. A.M.B. is supported by an International Macquarie University Research Excellence Scholarship (№. 2012219).

The authors declare no competing financial interests.

Correspondence should be addressed to Paul M. Pilowsky, The Heart Research Institute, 7 Eliza Street, Sydney, 2042 New South Wales, Australia. E-mail: paul.pilowsky@hri.org.au.

DOI:10.1523/JNEUROSCI.4058-14.2015

Copyright $\odot 2015$ the authors $\quad 0270-6474 / 15 / 352191-09 \$ 15.00 / 0$ adenylate cyclase, leading to two main effects on neurons. First, it is able to act as an excitatory neurotransmitter (Lai et al., 1997; Farnham et al., 2008; Farnham et al., 2011; Farnham et al., 2012) and, second, as a neuroprotective and anti-inflammatory agent by inhibiting the activation of mitogen activated protein kinase (MAPK) family and by stimulating secretion of IL-6 (Shioda et al., 1998). During seizures, there is an upregulation of MAPK in hippocampus and, in patients who are recovering from tonicclonic seizure, IL-6 is elevated in CSF (Peltola et al., 2000). Conversely, IL-6 knock-out mice are more susceptible to seizure-induced hippocampal damage (Penkowa et al., 2001), suggesting that IL-6 is neuroprotective. Nomura et al. (2000) showed that PACAP gene expression increases in the paraventricular nucleus of the hypothalamus after KA-induced temporal lobe epilepsy in rats. Based on these findings, we hypothesized that PACAP itself or its action on activated microglia has neuroprotective effects that inhibit seizure-induced neuronal excitation and protect against the adverse autonomic effects of seizure. Activated microglia are associated with neurodegeneration both in patients and animal models of temporal lobe epilepsy (Mirrione et al., 2010; Ahmadi et al., 2013); however, their action as either neurotoxic or neuroprotective in brainstem and spinal cord cardiovascular nuclei remains unclear. A number of recent studies suggest that microglia may acquire the neuroprotective 
M2 phenotype, and increase endogenous production of TGF- $\beta$ and IL-10 (Li et al., 2007; Mosser and Edwards, 2008; Neumann et al., 2008; Loane and Byrnes, 2010; Vinet et al., 2012). These findings led to our second hypothesis that microglia in cardiovascular nuclei may be neuroprotective and provide a defense mechanism by attenuating sympathoexcitatory cardiovascular responses during seizure.

This study therefore aimed to investigate the role of PACAP and microglia in seizure-induced cardiovascular responses. Specifically, the aims of this study were to determine the effect of intrathecal administration of PACAP and the PACAP antagonist PACAP(6-38) and the microglia antagonists minocycline and doxycycline on seizure-induced cardiovascular responses. We used in vivo physiological and pharmacological approaches in anesthetized rats using the KA-induced seizure model (Sakamoto et al., 2008).

\section{Materials and Methods}

Animals. All procedures and protocols were approved by the Animal Care and Ethics Committee of Macquarie University and the Sydney Local Health District. All experiments were conducted on adult male Sprague Dawley (SD) rats (250-350 g; Animal Resources Centre, Perth, Australia) in accordance with the Australian code of practice for the care and use of animals for scientific purposes.

Surgical preparation. Rats $(n=64)$ were anesthetized with $10 \%$ urethane (ethyl carbamate; $1.3-1.5 \mathrm{~g} / \mathrm{kg}$, i.p.; Sigma-Aldrich). The depth of anesthesia was monitored by observing reflex responses (withdrawal or pressor $>10 \mathrm{mmHg}$ ) to nociceptive stimuli (periodic tail/paw pinches). Additional anesthetic was injected $(30-40 \mathrm{mg}, 10 \%$ urethane i.v.), if reflex responses were observed. Atropine sulfate (100 $\mu \mathrm{g} / \mathrm{kg}$, i.p.; Pfizer) was administered with the first dose of urethane to prevent bronchial secretions. After the completion of the general surgical procedures described below, rats were secured in a stereotaxic frame with their abdomen resting on a heating blanket (TC-1000; CWE). Core body temperature was monitored with a rectal thermometer and maintained between 36.5 and $37.5^{\circ} \mathrm{C}$ throughout the experiment.

General surgical procedures. The right carotid artery and jugular vein were cannulated with polyethylene tubing [internal diameter (I.D.) = $0.50 \mathrm{~mm}$; outer diameter (O.D.) $=0.90 \mathrm{~mm}$; Microtube Extrusions] for recording of blood pressure, and for administration of drugs and fluids, respectively. A tracheostomy enabled mechanical ventilation (rodent ventilator; UGO Basile Biological Research Apparatus) and recording of expired $\mathrm{CO}_{2}$ (Capstar $100 \mathrm{CO}_{2}$ analyzer; CWE). Electrocardiogram (ECG) was recorded from leads connected to the forepaws of the rat and HR was derived from it. Rats were vagotomized, artificially ventilated with oxygen-enriched room air, and paralyzed with pancuronium bromide $(0.4 \mathrm{mg}$ given as a $0.2 \mathrm{ml}$ bolus i.v. injection, followed by an infusion of $10 \%$ pancuronium in $0.9 \%$ saline at a rate of $2 \mathrm{ml} / \mathrm{h}$; AstraZeneca). Arterial blood gases were analyzed with an electrolyte and blood gas analyzer (Vetstat; IDEXX). $\mathrm{PaCO}_{2}$ was maintained at $40.0 \pm 2$ and $\mathrm{pH}$ between 7.35 and 7.45. The left greater splanchnic sympathetic nerve at a site proximal to the celiac ganglion and the left phrenic nerves were isolated, dissected, and tied with 5/0 silk thread. Nerve activity was recorded using bipolar stainless steel electrodes. Signals were amplified (BMA-931 Bioamplifiers; CWE; sampling rate: $6 \mathrm{kHz}$, gain: 2000, filtering: $30-3000 \mathrm{~Hz}$ ) and filtered with a $50 / 60 \mathrm{~Hz}$ line frequency filter (Humbug; Quest Scientific).

Intrathecal catheter placement. The atlanto-occipital junction was exposed and a catheter (polyethylene tubing, O.D. $=0.50 \mathrm{~mm}$; I.D. $=0.20$ $\mathrm{mm}$; Microtube Extrusions) with a dead space of $\sim 6 \mu \mathrm{l}$ was inserted into the intrathecal space of all rats through a slit in the dura and advanced caudally to the level of T5/6.

Electroencephalogram electrode placement. For the placement of electroencephalogram (EEG) electrodes, the scalp over the dorsal surface of the skull was incised, the skin retracted, and the periosteum scraped from the skull surface. Burr holes were drilled bilaterally for recording over the dorsal hippocampus (5.2 $\mathrm{mm}$ anterior to lambda, $3 \mathrm{~mm}$ lateral to mid- line, and 2-3 mm below the skull surface) and electrode positions were confirmed with cresyl violet staining. A single electrode wire was inserted into each hole using stereotaxic manipulator. Electrodes were $75 \mu \mathrm{m}$ Teflon-insulated stainless steel wires (A-M Systems). Signals were amplified (BMA-931 Bioamplifier; CWE), band-pass filtered from $1 \mathrm{~Hz}$ to 10 $\mathrm{kHz}$, amplified $100 \times$, and digitized at $6 \mathrm{kHz}$ (see data acquisition below).

Seizure induction. Intraperitoneal injection of KA was used to generate a seizure/KA dose-response curve in SD rats (Figs. 1,2). Responses were recorded for at least $2 \mathrm{~h}$ after KA injection, during which continuous monitoring of EEG was used to identify the development of seizures. To determine the presence or absence of seizure, the amplitude of the AUC of the EEG before and after KA administration was measured. A seizure was considered to have occurred if the AUC increased by at least $50 \%$. In vehicle-treated rats, no change occurred. The log-transformed values of percent change in AUC at 60 and 120 min after injection relative to the AUC before injection in different groups are shown in the Results.

From the dose-response study, we found that $2 \mathrm{mg} / \mathrm{kg} \mathrm{KA}$ was sufficient to induce seizure and a significant increase in splanchnic sympathetic nerve activity (Figs. 1, 2) and was used for the rest of the study. At the conclusion of the experiments, rats were either killed with $0.5 \mathrm{ml}$ of 3 M potassium chloride ( $\mathrm{KCl}$, i.v.) or deeply anesthetized and perfused with $400 \mathrm{ml}$ of ice-cold $0.9 \%$ saline followed by $400 \mathrm{ml}$ of $4 \%$ paraformaldehyde solution. The brains were removed from the perfused rats and postfixed in the same fixative overnight. Brains were sectioned coronally $(100 \mu \mathrm{m})$ and stained with cresyl violet for histological verification of the electrode positions.

Intrathecal drug administration protocol. In all dose-response studies, a control injection of $10 \mu \mathrm{l}$ of $10 \mathrm{mmol} / \mathrm{L}$ PBS was washed in with $6 \mu \mathrm{l} \mathrm{PBS}$ $10 \mathrm{~min}$ before the intraperitoneal injection of KA. The same intrathecal PBS infusion protocol was followed for the vehicle control group of rats 10 min before intraperitoneal PBS injection.

The dose of PACAP-38 and the antagonist PACAP(6-38) (Auspep) for intrathecal infusion was selected from our previous study (Farnham et al., 2011). Ten microliters of $1 \mathrm{mmol} / \mathrm{L}$ PACAP(6-38) or $300 \mu \mathrm{mol} / \mathrm{L}$ PACAP was administered intrathecally and flushed in with $6 \mu$ of PBS. Doses determined from a previous study (Hua et al., 2005) for minocycline $(100 \mu \mathrm{g} / 10 \mu \mathrm{l})$ or doxycycline $(100 \mu \mathrm{g} / 10 \mu \mathrm{l})$ were administered intrathecally and flushed in with $6 \mu \mathrm{l}$ of PBS. In all groups of rats, intrathecal infusion was made 10 min before intraperitoneal KA or PBS injection. All infusions were made over a $10-15 \mathrm{~s}$ period, as described previously (Farnham et al., 2008). At the conclusion of experiments, the rats were killed as described above. Postmortem verification of the position of catheter tip was performed by exposing the spinal cord and checking its position with respect to the vertebra.

Data acquisition and analysis. Data were acquired using an ADC system (CED 1401; Cambridge Electronic Design) and Spike 2 acquisition and analysis software (version 8.01; Cambridge Electronic Design). The EEG activity raw data were DC removed. The amplitude of EEG activity (AUC) was analyzed in 5 min blocks taken 1 min before intrathecal infusion and 60 and 120 min after intraperitoneal injection of either KA or PBS. The percentage change in EEG AUC was calculated for each rat at 60 and 120 min after treatment compared with pretreatment area (taken as $100 \%$ ) and grouped together. Phrenic nerve activity (PNA) was rectified and smoothed $(\tau 0.5 \mathrm{~s})$. PNA was analyzed from 1 min blocks taken $1 \mathrm{~min}$ before intrathecal infusion and 60 and $120 \mathrm{~min}$ after intraperitoneal injection of either KA or PBS. The percent change in area under curve was analyzed at 60 and 120 min compared with pretreatment area (taken as $100 \%)$. SNA raw data were rectified and smoothed $(\tau 2 \mathrm{~s})$ and normalized to zero by subtracting the residual activity $5-10 \mathrm{~min}$ after death. SNA was analyzed with a sigmoid curve-fit analysis method. A sigmoid curve was fitted to the processed SNA channel and the percentage low, percentage high, percentage range, and slope (\%/s) were calculated (only percentage range is showed in graphs). Mean arterial pressure (MAP) and HR were analyzed from 1 min blocks taken 1 min before intrathecal infusion and the time at which it was peaked. End-tidal $\mathrm{CO}_{2}$ and core temperature were analyzed from 1 min blocks taken $1 \mathrm{~min}$ before intrathecal infusion and intraperitoneal injection and 30, 60, 90, and 120 min after intraperitoneal injection of either KA or PBS. Arterial blood gas levels $\left(\mathrm{PaCO}_{2}\right.$ and $\left.\mathrm{pH}\right)$ were measured $10 \mathrm{~min}$ before intrathe- 


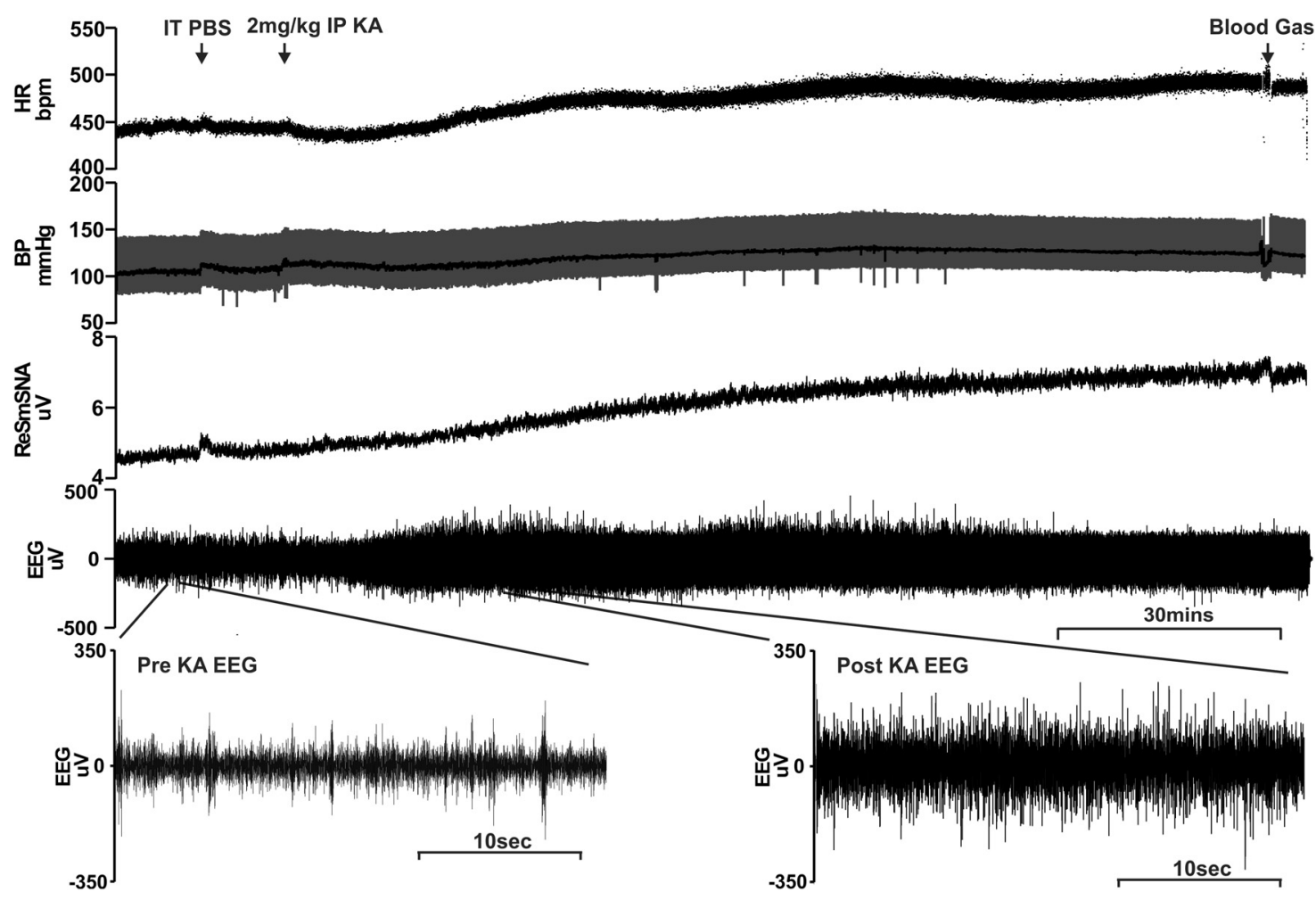

Figure 1. Effect of intrathecal (IT) PBS (10 $\mu$ l) followed by $2 \mathrm{mg} / \mathrm{kg}$ intraperitoneal $\mathrm{KA}$ in an anesthetized rat (see Materials and Methods) on (from the top): $\mathrm{HR}$ (bpm), BP (mmHg), SNA ( $\mu \mathrm{V}$ ), and EEG $(\mu \mathrm{V})$. Time of administration of IT PBS and intraperitoneal KA are marked with an arrow. Pre-KA EEG and post-KA EEG refer to the expanded periods as indicated.
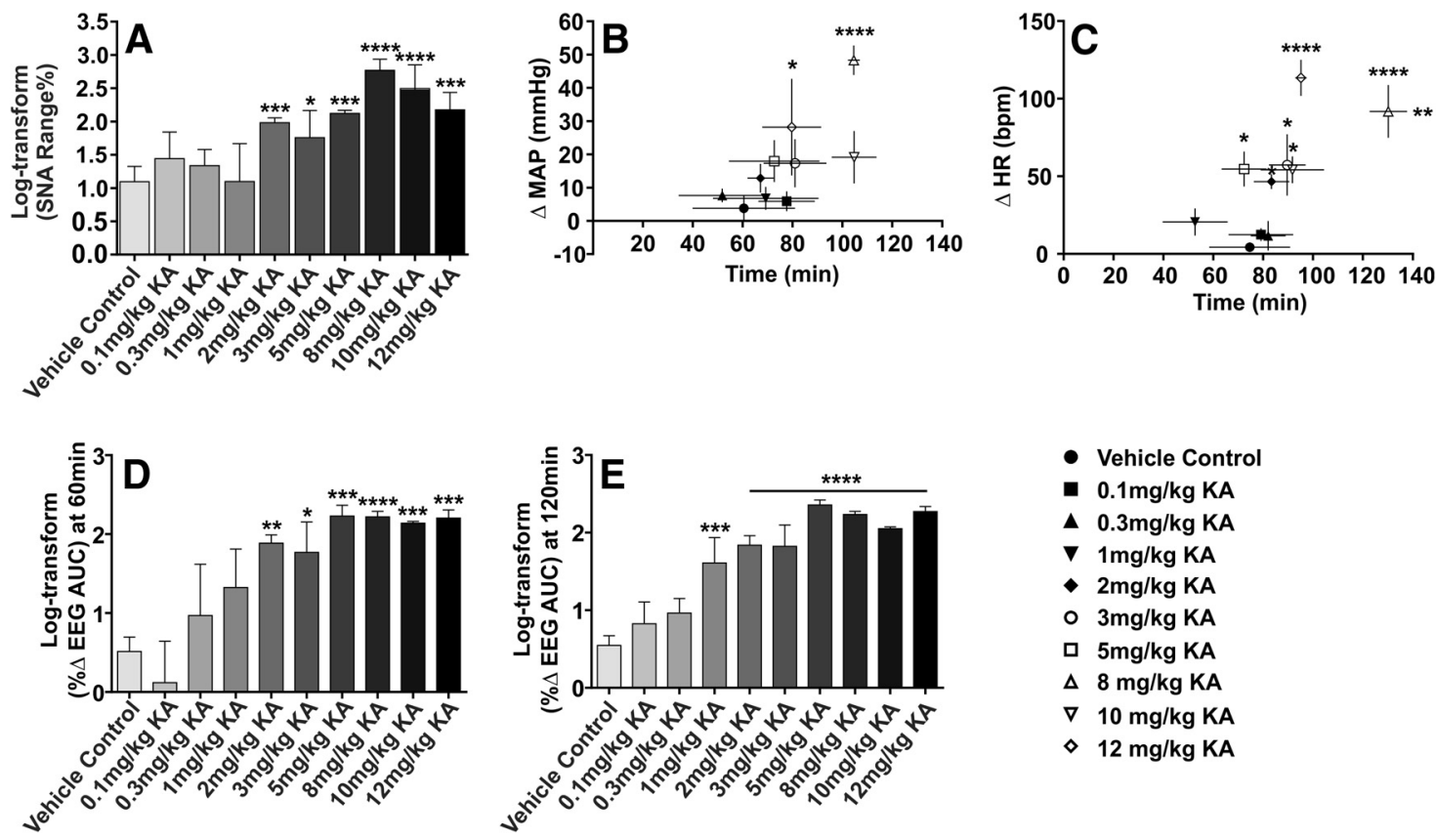

Figure 2. Dose-response curve for intraperitoneal KA. Change in SNA (log transform of percentage range) ( $\boldsymbol{A}$ ), maximum change in MAP (on $y$-axis) at respective time point after intraperitoneal PBS or KA injection (on $x$-axis) (B), maximum change in HR (on $y$-axis) at respective time point after intraperitoneal PBS or KA injection (on $x$-axis) ( () and log transform of percentage change in AUC of EEG activity at $60 \mathrm{~min}(\boldsymbol{D})$ and $120 \mathrm{~min}(\boldsymbol{E})$ after intraperitoneal PBS or KA injection, in PBS $(n=5)$ and $0.1(n=3), 0.3(n=3), 1(n=3), 2(n=5), 3(n=3), 5(n=3), 8(n=3), 10(n=$ $3)$, and $12(n=3) \mathrm{mg} / \mathrm{kg}$ intraperitoneal KA-treated rats. Statistical significance was determined using one-way ANOVA followed by $t$ tests and Dunnett's correction to compare effects with the control value. Data are expressed as mean \pm SEM. ${ }^{* * *} p \leq 0.0001 ; * * * 0.001 ; * * 0.01$ and ${ }^{* *} p \leq 0.05$ compared with vehicle control group.

cal infusion and 120 min after KA or PBS injections in all animals. Log transformation was applied to EEG and SNA raw values where necessary if variances were not normally distributed or heterogeneous. Statistical analysis was performed in GraphPad Prism software (version 6.04).
Statistical significance was determined using one-way ANOVA followed by $t$ tests with Dunnett's correction for dose-response studies and with the Holm-Sidak correction for the rest of the study. Multiple comparisons were done between groups. $p \leq 0.05$ was considered significant. 

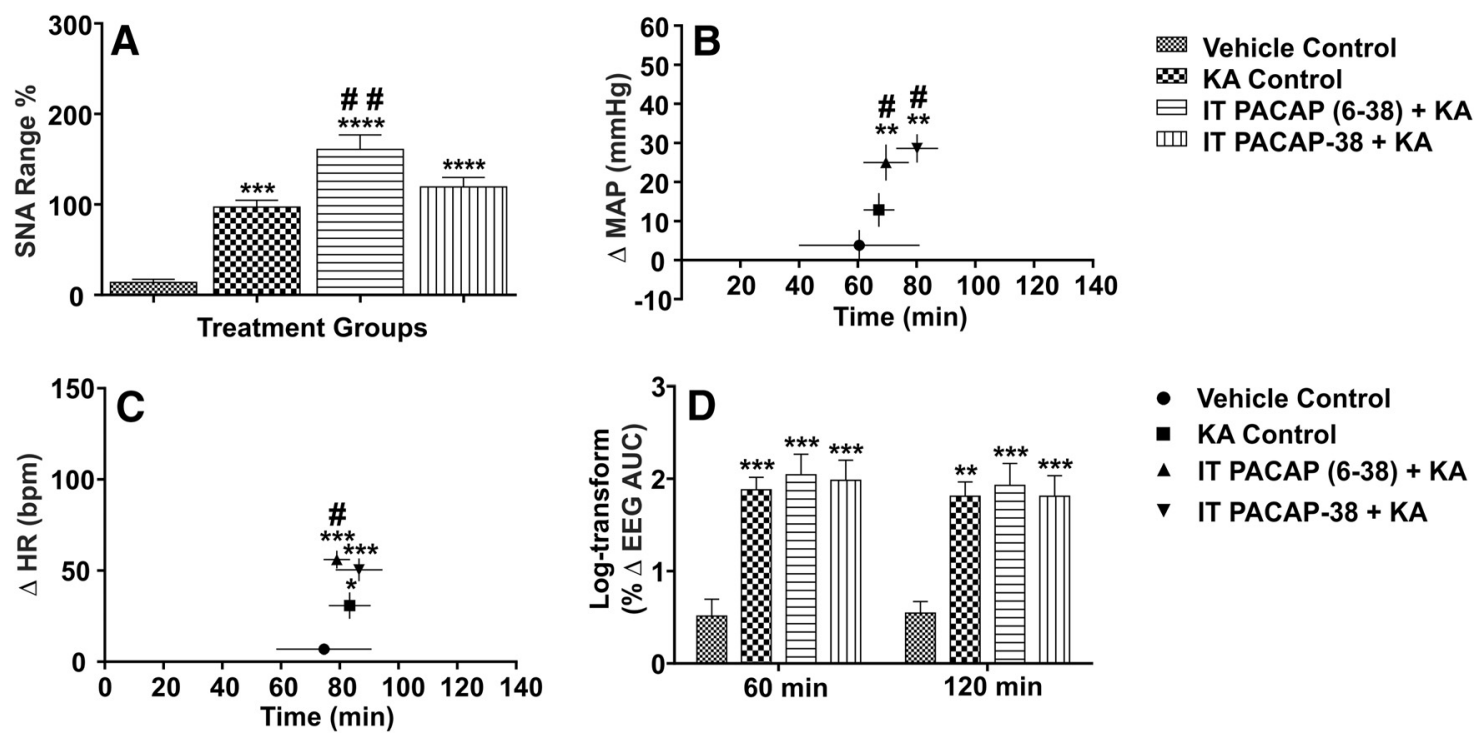

Figure 3. In vivo effects of intrathecal (IT) PACAP(6-38) and PACAP-38 in $2 \mathrm{mg} / \mathrm{kg} \mathrm{KA-induced} \mathrm{seizure} \mathrm{rats.} \mathrm{Change} \mathrm{in} \mathrm{SNA} \mathrm{( \%} \mathrm{range)} \mathrm{(A),} \mathrm{maximum} \mathrm{change} \mathrm{in} \mathrm{MAP} \mathrm{(on} y$-axis) at respective time point after intraperitoneal PBS or KA injection (on $x$-axis) (B), maximum change in HR (on $y$-axis) at respective time point after intraperitoneal PBS or KA injection (on $x$-axis) ( $\boldsymbol{C}$, and log transform of percentage change in AUC of EEG activity at 60 and 120 min after intraperitoneal PBS or KA injection (D) in different groups of rats after development of seizure. In all groups, $n=5$. Statistical significance was determined using one-way ANOVA followed by $t$ tests with a Holm-Sidak correction. Data are expressed as mean \pm SEM. ${ }^{* * * *} p \leq 0.0001 ;{ }^{* * *} p \leq 0.001 ;{ }^{* *} p \leq 0.01 ;{ }^{*} p \leq 0.05$ compared with vehicle control group; \#\#p $\leq 0.01$ and \#p $\leq 0.05$ compared with KA control group.

Calculation of corrected QT interval. Because the length of the QT interval can be affected by heart rate, corrected QT (QTc) interval was calculated by dividing the QT interval in seconds by the square root of the R-R interval in seconds (Bazett, 1920). The QTc was obtained in all rats before and after vehicle or KA injection.

\section{Results}

KA-induced seizures causes sympathoexcitation, tachycardia, and pressor responses

Intraperitoneal injection of KA in urethane anesthetized rats (Fig. 1) was used to determine the most effective dose for use in this study (Fig. 2). One-way ANOVA of peak EEG AUC responses revealed that the $2 \mathrm{mg} / \mathrm{kg}$ was the lowest dose of KA effective in significantly elevating EEG (120 min after KA: $64.0 \pm 17.7 \%$; $p \leq$ 0.0001; Fig. $2 D, E$ ), SNA (\% range: $97.2 \pm 7.4 \%$; $p \leq 0.001$; Fig. $2 A)$ and $\operatorname{HR}(\Delta \mathrm{HR}: 46.5 \pm 4.8 \mathrm{bpm} ; p \leq 0.05$; Fig. $2 C)$. Therefore, a $2 \mathrm{mg} / \mathrm{kg}$ dose of KA was used in the rest of the study. SNA percentage low was same in all groups, whereas percentage high was significantly different in $2 \mathrm{mg} / \mathrm{kg}(194.3 \pm 6.0 \%$; $p \leq 0.05)$ and in all higher doses of KA compared with vehicle-treated group. The change in MAP was significantly higher only in 8 ( $\Delta$ MAP: $48.3 \pm 4.5 \mathrm{mmHg} ; p \leq 0.0001)$ and $12 \mathrm{mg} / \mathrm{kg}$ ( $\Delta$ MAP: $28.2 \pm 14.6 \mathrm{mmHg} ; p \leq 0.05$ ) doses of KA compared with vehicle control, whereas the change in HR was significantly different in 2 $\mathrm{mg} / \mathrm{kg}$ and all higher doses of KA compared with vehicle control. There were no significant differences in PNA, expired $\mathrm{CO}_{2}$, and rectal temperature in any of the groups studied (results not shown). Blood gas analysis revealed that blood $\mathrm{PaCO}_{2}$ and $\mathrm{pH}$ were within normal physiological range in all animals $\left(\mathrm{PaCO}_{2}\right.$ was $40.0 \pm 2$ and $\mathrm{pH}$ between 7.35 and 7.45). There was no significant change in pretreatment and posttreatment blood $\mathrm{PaCO}_{2}$ and $\mathrm{pH}$ levels (results not shown). A $2 \mathrm{mg} / \mathrm{kg}$ intraperitoneal injection of KA increased EEG amplitude beyond $50 \%$ of baseline and was classified as a seizure. The EEG seizure response was followed by an increase in SNA (Fig. 1). Importantly, SNA did not begin to increase before the first instance of seizure, eliminating the possibility of the increase in SNA being due to a peripheral effect of KA. The EEG activity started to increase at
$25.6 \pm 3.6 \mathrm{~min}$ after KA injection, followed by SNA, MAP, and HR. SNA, EEG, and HR were significantly increased after KA injection compared with the vehicle-treated group.

\section{Antagonism of PACAP exacerbates the cardiovascular effects of seizure}

The PACAP antagonist PACAP(6-38) was administered intrathecally to test the hypothesis that PACAP has a neuroprotective and anti-inflammatory role in KA-induced seizure rats that might be responsible for attenuating the seizure-induced sympathoexcitation. The seizure-induced cardiovascular responses were significantly increased by infusing PACAP(6-38) $10 \mathrm{~min}$ before KA injection (Fig. $3 A-C$ ) compared with the KA control group (SNA high: $255.1 \pm 15.3 \% ; p \leq 0.01$, SNA range: $160.8 \pm$ $16.0 \%$; $p \leq 0.01$, Fig. $3 A$; SNA slope: $0.043 \pm 0.0095 \% / s ; p \leq$ 0.01, $\Delta$ MAP: $31.84 \pm 3.5 \mathrm{mmHg} ; p \leq 0.05$, Fig. $3 B$; and $\Delta \mathrm{HR}$ : $56.1 \pm 4.9$ beats/min; $p \leq 0.05$, Fig. $3 C$ ). Intrathecal infusion of $300 \mu \mathrm{mol} / \mathrm{L}$ PACAP had no effect on the SNA increase in response to KA-induced seizure (Fig. $3 A$ ). Intrathecal PACAP agonist and antagonist treatment had no effect on EEG activity in seizure-induced rats compared with the KA control group (Fig. 3D)

\section{Microglia antagonism worsens the cardiovascular dysfunction in seizure}

The effect of blocking microglial activation on seizure-induced cardiovascular responses was evaluated at the spinal cord level. Intrathecal injection of the microglia antagonists minocycline and doxycycline in KA-induced seizure rats more than doubled the sympathoexcitatory and MAP responses, but did not affect HR. The microglia antagonists alone had no effect on measured cardiovascular parameters in vehicle-treated control rats (Fig. $4 A-C)$. These results indicate that microglia have a neuroprotective or anti-inflammatory role during seizure. Intrathecal minocycline significantly increased sympathoexcitation in KA-induced seizure rats compared with the KA control group (SNA high: $314.1 \pm 33.4 \%$; $p \leq 0.01$, SNA range: $224.8 \pm 33.6 \%$; 

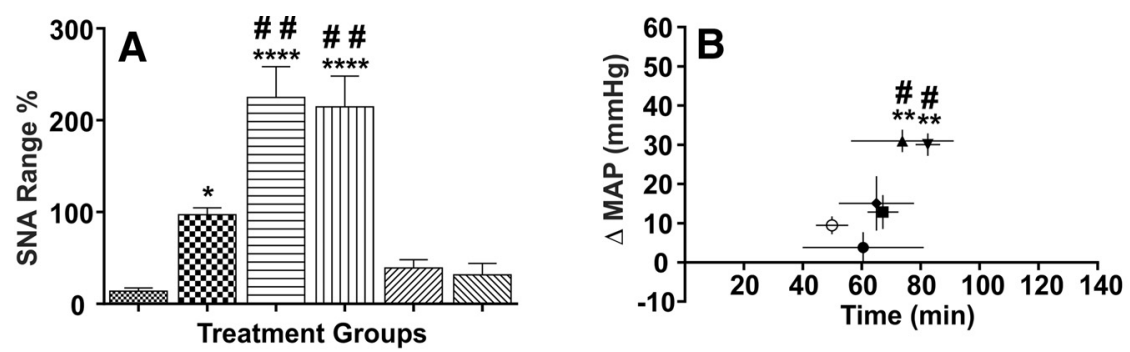

- Vehicle Control

- KA Control

- IT minocycline + KA

V IT doxycycline + KA

- IT minocycline + PBS

○ IT doxycycline + PBS
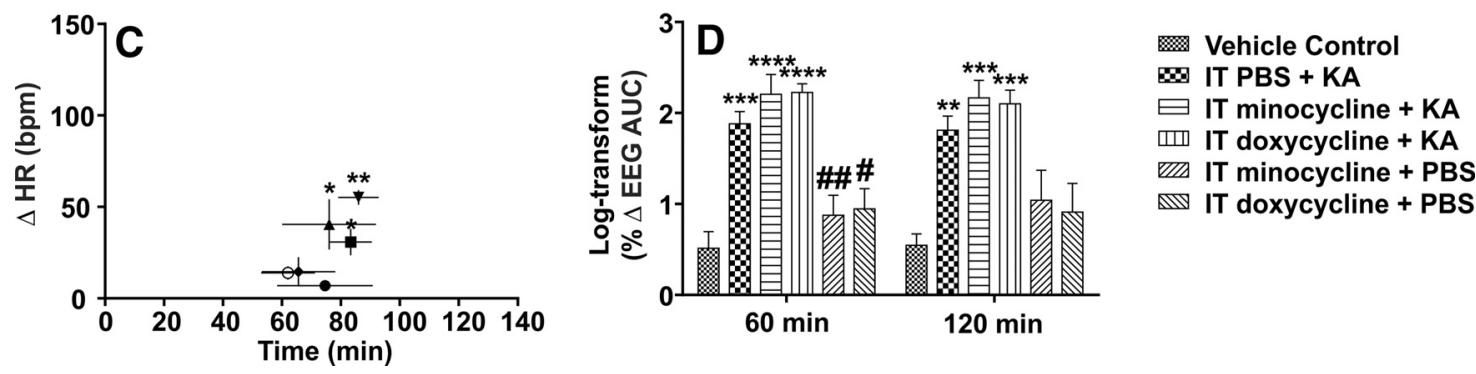

Figure 4. In vivo effects of intrathecal (IT) minocycline and doxycycline in $2 \mathrm{mg} / \mathrm{kg} \mathrm{KA-induced} \mathrm{seizure} \mathrm{rats} \mathrm{and} \mathrm{vehicle} \mathrm{control} \mathrm{rats.} \mathrm{Change} \mathrm{in} \mathrm{SNA} \mathrm{( \%} \mathrm{range)} \mathrm{(A),} \mathrm{maximum} \mathrm{change} \mathrm{in} \mathrm{MAP} \mathrm{(on}$ $y$-axis) at respective time point after intraperitoneal PBS or KA injection (on $x$-axis) (B), maximum change in HR (on $y$-axis) at respective time point after intraperitoneal PBS or KA injection (on $x$-axis) (C), and log transform of percentage change in AUC of EEG activity at 60 and 120 after intraperitoneal PBS or KA injection (D) in different groups of rats after development of seizure. In all groups, $n=5$. Statistical significance was determined using one-way ANOVA followed by $t$ tests with a Holm-Sidak correction. Data are expressed as mean \pm SEM. ${ }^{* * * *} p \leq 0.0001 ;{ }^{* * *} p \leq 0.001 ;{ }^{* *} p \leq$ $0.01 ; * 0 \leq 0.05$ compared with vehicle control group; \#\#p $\leq 0.01$ and $\# p \leq 0.05$ compared with KA control group.

$p \leq 0.01$, Fig. $4 A$; and SNA slope: $0.04 \pm 0.006 \% / s ; p \leq 0.05)$. A similar response was observed with intrathecal doxycycline, which augmented the sympathoexcitation in KA-induced seizure rats compared with the KA control group (SNA high: $313.2 \pm$ $31.0 \%$; $p \leq 0.01$, SNA range: $214.5 \pm 33.6 \%$; $p \leq 0.01$, Fig. $4 A$; and SNA slope: $0.05 \pm 0.008 \% / s ; p \leq 0.01)$. MAP was also significantly increased in both minocycline- and doxycyclinetreated rats after KA treatment compared with the KA control group ( $\triangle$ MAP: $31.0 \pm 2.9 \mathrm{mmHg} ; p \leq 0.05$ and $30.0 \pm 2.9$ $\mathrm{mmHg} ; p \leq 0.05$, respectively; Fig. $4 B$ ). There was no significant difference in the HR response between the intrathecal microglia antagonist treatment in the seizure-induced group and the KA control groups (Fig. 4C). Intrathecal minocycline and doxycycline treatment in the KA-induced seizure group had no effect on EEG activity compared with KA control (Fig. 4D).

\section{Proarrhythmogenic changes in ECG after seizure}

In vehicle-treated rats, changes in QTc interval $(\Delta \mathrm{QT} c)$ duration between pretreatment intraperitoneal PBS injection and $120 \mathrm{~min}$ after injection was $2.5 \pm 1.0 \mathrm{~ms}$ (Fig. 6). The $\Delta \mathrm{QTc}$ interval was significantly increased in seizure-induced rats compared with vehicle control (13.1 $\pm 1.5 \mathrm{~ms} ; p \leq 0.001$; Fig. 6). Compared with the vehicle control group, the $\triangle \mathrm{QT}$ c interval duration was significantly increased in the KA control, intrathecal PACAP-, PACAP (6-38)-, and doxycycline-treated groups, but not in the minocycline-treated group (also seen in Fig. 5). The QT interval was prolonged in KA control, PACAP (6-38)-, PACAP-, and doxycycline-treated rats compared with vehicle treatment (Fig. 5). PACAP antagonist treatment not only prolongs the QT interval, but also causes a clear ST segment elevation (Fig. 5C, arrows), both of which are prominent proarrhythmogenic changes (HRtriggered ECG was drawn pretreatment and posttreatment and shown in the right side corner of each graph; Fig. 5). Intrathecal minocycline treatment in the KA-treated group showed significant differences in $\triangle \mathrm{QT}$ c interval compared with the KA control group ( $p \leq 0.01$; Fig. 6$)$.

\section{Discussion}

The main findings of the study are, first, that sympathetic nerve activity begins to rise several minutes after the start of a seizure. Second, we find that induction of seizure activity in the hippocampal EEG that follows intraperitoneal KA is associated with significant and dose-dependent increases in SNA, MAP, and HR and a prolongation of the QT interval. Third, in KA-induced seizure rats, intrathecal administration of the PACAP antagonist PACAP (6-38) exacerbates the cardiovascular responses, whereas intrathecal administration of PACAP has no beneficial effect. Fourth, intrathecal infusion of tetracycline-derived microglia antagonists exacerbates the cardiovascular responses after the induction of seizures. Overall, antagonism of PACAP or microglia tends to worsen the sympathoexcitatory effects of seizures.

Our work demonstrates that KA-induced seizure has a powerful effect on the cardiovascular system. It increases SNA, MAP, and HR; prolongs QTc; and, after PACAP antagonist, causes ST elevation. Together, these changes markedly increase the risk of arrhythmia. The present study revealed a neuroprotective role of endogenous PACAP that is antagonized by intrathecal infusion of PACAP(6-38) in KA-induced seizure rats. Therefore, PACAP attenuates KA seizure-induced sympathoexcitation. The failure to see a beneficial effect of PACAP agonist infusion may be due to an inadequate dose being provided. Alternatively, local neurons secreting PACAP may cause a maximal effect on local PACAP receptors so that additional intrathecal doses of PACAP provided exogenously have no effect. This creates the need for further study of the effect of PACAP during seizure on catecholaminergic and other bulbospinal sympathoexcitatory neurons in the rostral ventrolateral medulla (Schreihofer and Guyenet, 1997). It is possible that microinjection of low doses of exogenous PACAP in rostral ventrolateral medulla might provide an additional neuroprotective effect during seizure and inhibit the sympathoexcitation. Microglia are activated by increased phosphorylation of the MAPK pathway. PACAP act on microglia via membrane- 

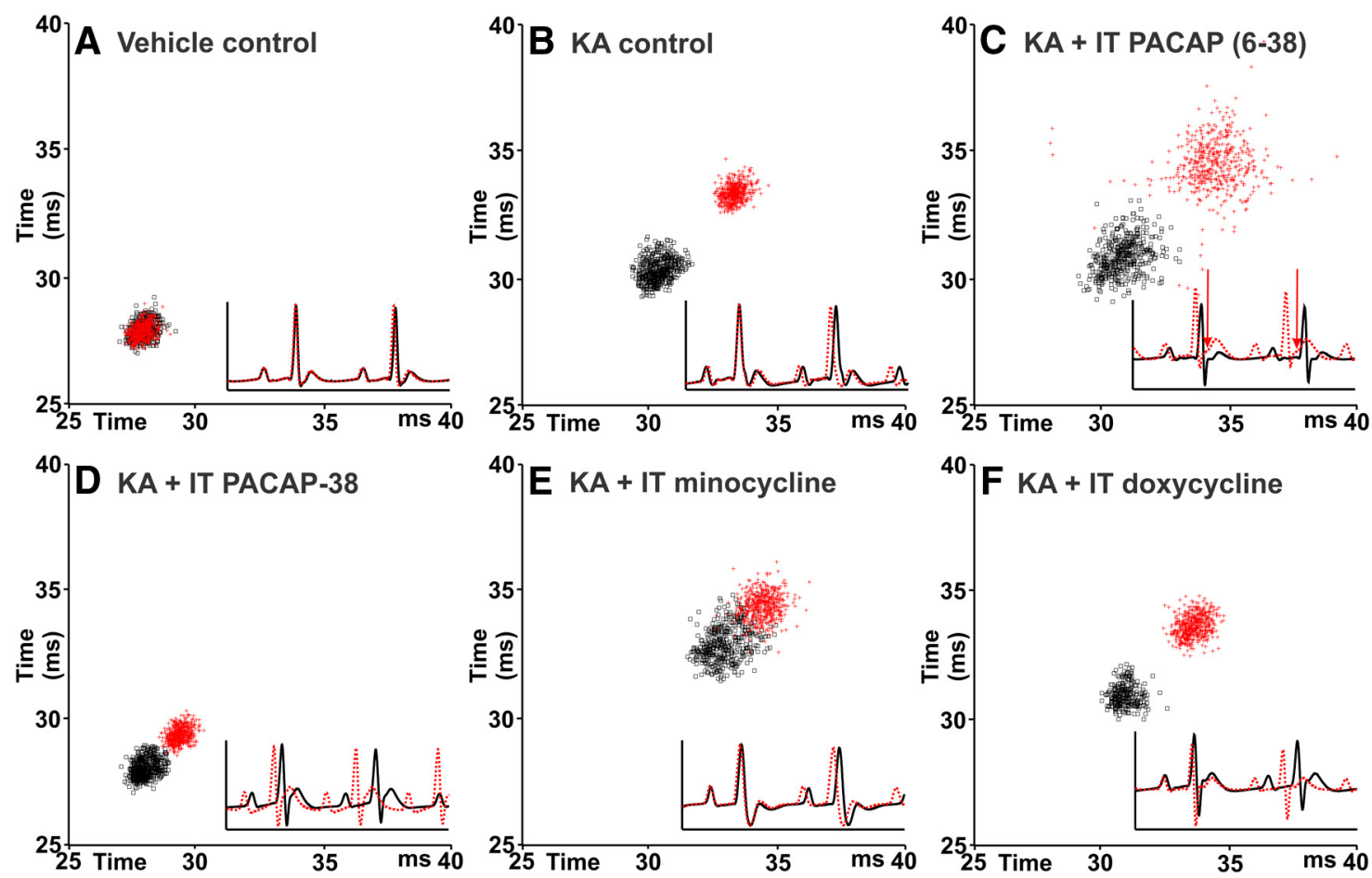

Figure 5. Representative Poincare plots illustrate the increase in QT interval after KA-induced seizures in individual rats (group data in Fig. 6). Black box symbols show pre-PBS and red plus symbols show $120 \mathrm{~min}$ post-PBS or KA intraperitoneal injection in the respective groups. A, Pre- (black) and $120 \mathrm{~min}$ post- (red) vehicle. B, Pre- (black) and 120 min post- (red) KA. C, Pre- (black) and 120 min post-KA with IT PACAP (6-38) (red). D, Pre- (black) and 120 min post-KA with IT PACAP-38 (red). E, Pre- (black) and 120 min post-KA with intrathecal (IT) minocycline (red). $\boldsymbol{F}$, Pre- (black) and 120 min post-KA with IT doxycycline (red). Scale bar in milliseconds. HR-triggered ECG was drawn pre- and posttreatment and is shown in the right corner of each box (continuous black and dotted red lines represent pretreatment and posttreatment E(G). ST segment elevation is shown with an arrow (C).

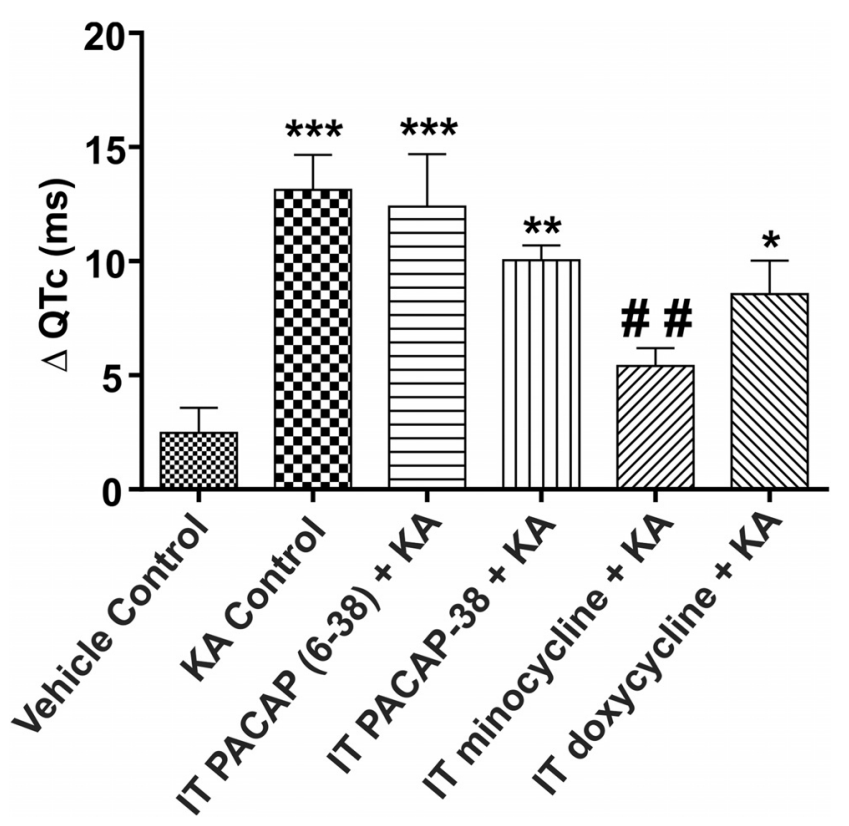

Figure 6. Group data showing increase in QTcinterval 120 min after intraperitoneal injection of KA or PBS in the different groups of rats (see also Fig. 5). IT, Intrathecal. Statistical significance was determined using one-way ANOVA followed by $t$ tests with a Holm-Sidak correction. Data are expressed as mean \pm SEM. ${ }^{* * * *} p \leq 0.0001 ;{ }^{* * *} p \leq 0.001 ;{ }^{* *} p \leq 0.01 ;{ }^{*} p \leq 0.05$ compared with vehicle control group; \#\# $\leq 0.01$ compared with the KA control group.

associated VPAC1 (PACAP) receptors, causing the release of substances such as IL- 10 or TGF- $\beta$, compounds that protect neurons from overexcitation (Fig. 7). The finding that an increase in sympathetic activity after PACAP antagonism with $\mathrm{PACAP}(6-38)$ or of microglial antagonism (doxycycline and minocycline) suggests that, in this model of epilepsy, there is strong activation of a neuroprotective PACAP and microglial pathway. The physiological effect of PACAP on microglia may act to dampen the sympathoexcitatory effects of seizure, an idea that is strengthened by the finding that tetracycline drugs had no effect in vehicle-treated animals.

To investigate the role of sympathoexcitation in acute seizure, we used a urethane-anesthetized, KA-induced model of seizure in rat. A single injection of KA in the range of 6-15 mg/ $/ \mathrm{kg}$, leads to a syndrome of recurrent status epilepticus, with each seizure lasting $30 \mathrm{~min}$ or longer over a prolonged period in conscious rats (Lévesque and Avoli, 2013). At these doses, it is well known that seizure activity causes autonomic dysfunction with acute cardiovascular changes (Sakamoto et al., 2008; Hotta et al., 2009). Here, we aimed to determine the lowest dose of KA that elicited seizure and sympathoexcitation. It is possible that this sympathoexcitation might be responsible for progressive deterioration of cardiovascular function in susceptible individuals and ultimately SUDEP. Several studies in human subjects during electroconvulsive therapy (ECT) reported changes in ECG that are proarrhythmogenic or ischemic. Because patients having seizures during ECT are under general anesthetic and neuromuscular blockade (Mokriski et al., 1992; Luckhaus et al., 2008), it is likely that any autonomic features would be blunted. Nevertheless, the finding that changes do occur suggests that seizures occurring during daily life would exhibit worse changes in ECG.

We aimed to elucidate PACAP-dependent differences in seizure-induced sympathoexcitation and a neuroprotective role of PACAP. PACAP exerts its autocrine neuroprotective (Shioda et al., 1998; Reglodi et al., 2000) and paracrine anti-inflammatory (Shioda et al., 2006; Ringer et al., 2013) effects in two ways. 


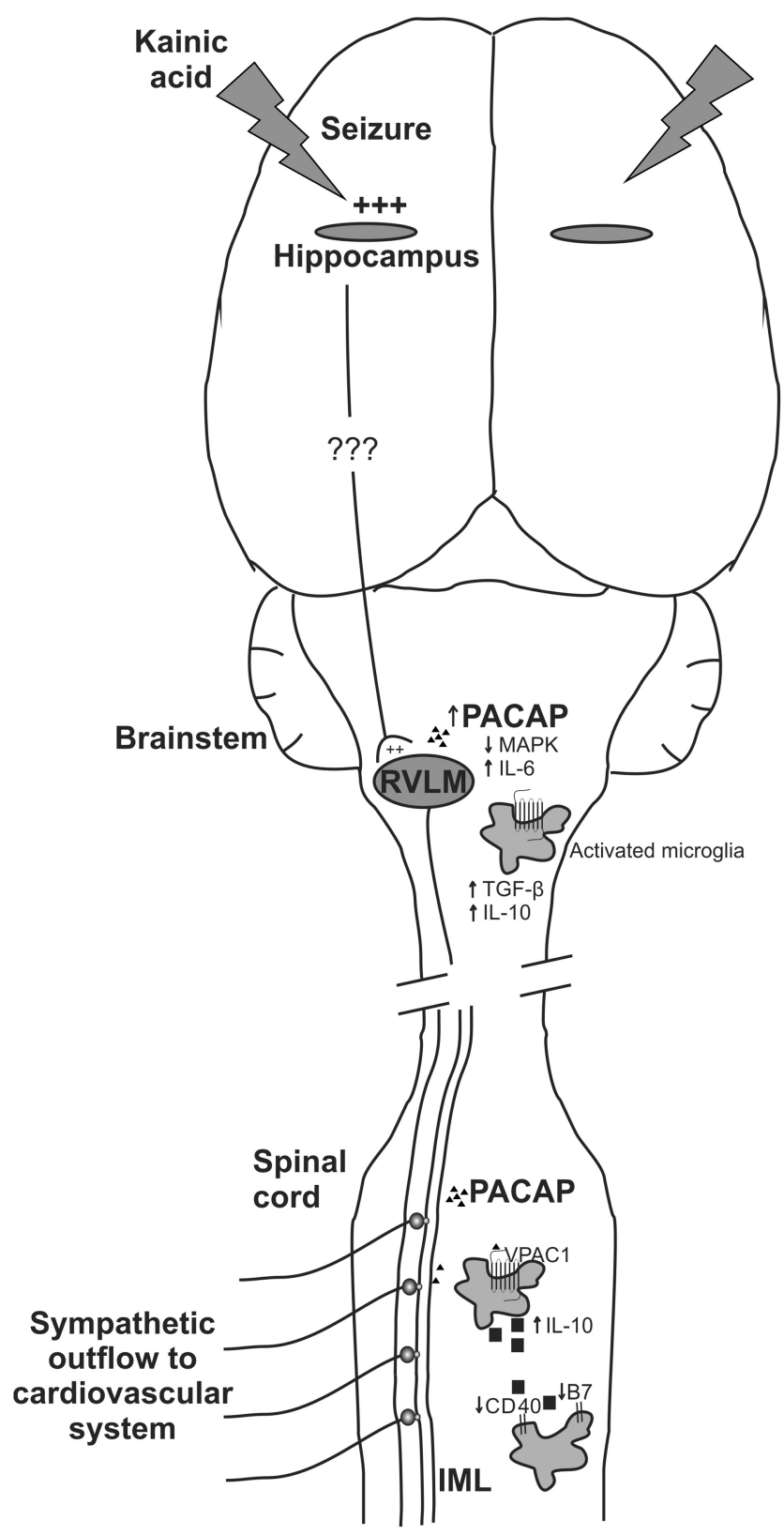

Figure 7. A proposed mechanism by which PACAP and microglia may have protective effects on sympathetic neurons in the brainstem and spinal cord during seizure. Seizure activates brainstem presympathetic neurons and changes cardiac and vascular reactivity. In seizure, microglia respond by changing from a quiescent surveillance state toward a more activated state. Activated microglia produce neurotropic and anti-apoptotic molecules, including TGF- $\beta$ and IL-10. These molecules have protective effects on sympathetic neurons. Seizure increases the expression of PACAP, which inhibits the activation of MAPK and stimulates the secretion of IL-6 into the CSF. PACAP then acts on microglial VPAC1 receptors to cause increased IL-10 protein expression, followed by downregulation of the expression of the pro-inflammatory receptors CD10 and B7.

PACAP not only inhibits the activation of members of the MAPK family such as c-Jun N-terminal kinase (JNK) (Shioda et al., 1998), but also stimulates the secretion of IL-6 in CSF (Gottschall et al., 1994; Shioda et al., 1998). This effect may be the mechanism of action of PACAP in attenuating seizure-induced sympathoexcitation (Fig. 7). An increased activity of MAPKs in seizure (Jeon et al., 2000; Ferrer et al., 2002) is associated with cell death in several experimental paradigms (Chan et al., 2003; Sakon et al., 2003). Although there are controversies about the pro- inflammatory and anti-inflammatory properties of IL-6, increased levels are reported to have neuroprotective effects on sympathetic neurons (März et al., 1998) and neuroprotective and antiinflammatory effects in KA-induced seizure rats (Penkowa et al., 2001). Nomura et al. (2000) showed that PACAP gene expression increases in the paraventricular nucleus of the hypothalamus after KA-induced temporal lobe epilepsy in rats. Our findings suggest a mechanistic role for PACAP during epilepsy because blockade of PACAP activity during acute seizure has a detrimental effect on seizure-induced cardiovascular dysfunction. Microglia activated during seizure also express costimulatory molecules CD40 and B7 that may lead to further activation of microglia. PACAP, acting on microglial VPAC1 receptors (Delgado et al., 1999), increases IL-10 protein expression, causing a downregulation of CD40 and B7 mRNA expression in activated microglia, thereby acting as a potent anti-inflammatory agent (Delgado et al., 1999; Kim et al., 2002). We propose that this effect of PACAP is a likely mechanism of action for the responses observed in this study (Fig. 7).

Microglia are the innate immune cells of the CNS and represent $\sim 10 \%$ of the total brain cell population. Microglia can be either neuroprotective or neurodegenerative depending on circumstances (Mosser and Edwards, 2008; Loane and Byrnes, 2010; Benarroch, 2013; Biber et al., 2014). There is extensive microglial activation in animal models of seizure (Beach et al., 1995; Drage et al., 2002; Shapiro et al., 2008) and preconditioning of hippocampal microglia during the acute phase seizure results in a neuroprotective effect (Mirrione et al., 2010). Other studies report a neuroprotective role of microglia in different animal models of neurodegenerative diseases (Li et al., 2007; Lai and Todd, 2008; Mosser and Edwards, 2008; Neumann et al., 2008; Loane and Byrnes, 2010; Vinet et al., 2012; Benarroch, 2013; Biber et al., 2014) such as ischemic injury (Kitamura et al., 2004; Kitamura et al., 2005; Imai et al., 2007; Lalancette-Hébert et al., 2007) and chronic stress-induced depression (Kreisel et al., 2014). Until now, a role for microglia in seizure-induced cardiovascular responses was unclear. Our results demonstrate that inhibition of microglial activation and proliferation during KA-induced seizure worsens sympathoexcitation. The microglial antagonists minocycline and doxycycline act by inhibiting the p38 MAPK pathway. Current findings suggest a neuroprotective potential of activated microglial cells on sympathetic preganglionic neurons. This neuroprotective effect of microglia may occur through an endogenous production of neurotropic and anti-apoptotic molecules such as TGF- $\beta$ and IL-10 (Benarroch, 2013) or by increased glutamate uptake (Persson and Rönnbäck, 2012). In this scenario, TGF- $\beta$ - and IL-10-mediated activation of microglia into regulatory or M2 type has potent anti-inflammatory and neuroprotective potential.

Resident microglia actively survey their environment and are referred to as "surveilling microglia" (Nimmerjahn et al., 2005). Activated microglia dynamically change into two different phenotypes, M1 or M2, that are generally considered to be inflammatory and protective respectively depending on the type of stimulus and microenvironment, participating not only in mechanisms of injury, but also in neuroprotection, repair, and circuit refinement in the CNS (Mosser and Edwards, 2008). Our current findings suggest that acute seizure causes microglia to adopt the M2 phenotype and protect sympathetic neurons from excitotoxicity. The neuroprotective effect on sympathetic neurons may be due to microglial production of IL-10. Inhibiting microglial activation with intrathecal minocycline or doxycycline infusion in seizure-induced rats increased sympathoexcitation, leading to in- 
creased HR and BP. Recent phase 3 clinical trials of minocycline in amyotrophic lateral sclerosis (ALS) patients showed that minocycline has a harmful effect on an ALS functional rating scale and greater mortality during the 9-month treatment phase compared with placebo treatment (Gordon et al., 2007). These findings are consistent with our current findings, which suggest that microglia antagonists worsen the effect of cardiovascular dysfunction during seizure. Overall, we propose that microglial activation during acute seizure has a neuroprotective effect due to adoption of the M2 phenotype or "protective" state. Microglial inactivation during acute seizure produces more neuroexcitation and cardiovascular dysfunction.

In conclusion, low doses of $\mathrm{KA}$, which are adequate to produce seizures, lead to slowly developing, but prolonged and significant increases in SNA, MAP, HR, and EEG activity and a prolongation of the QTc interval. This type of severe disruption in central autonomic function may ultimately lead to progressive deterioration of cardiovascular function and SUDEP.

The clinical implications of our findings are that PACAP may exert a protective role against known adverse cardiovascular effects of seizure because antagonism of the PACAP receptor exacerbated the seizure-induced cardiovascular effects. PACAP may exert neuroprotective effects by preventing the activation of MAPKs and increasing levels of IL- 6 and by its action on microglia. Together, our findings suggest that targeting PACAP and microglial activation may provide new therapeutic avenues in the prevention of seizure-induced cardiovascular dysfunction and SUDEP.

\section{References}

Ahmadi A, Sayyah M, Khoshkholgh-Sima B, Choopani S, Kazemi J, Sadegh M, Moradpour F, Nahrevanian H (2013) Intra-hippocampal injection of lipopolysaccharide inhibits kindled seizures and retards kindling rate in adult rats. Exp Brain Res 226:107-120. CrossRef Medline

Bazett HC (1920) An analysis of the time-relations of electrocardiograms. Heart 7:353-370.

Beach TG, Woodhurst WB, MacDonald DB, Jones MW (1995) Reactive microglia in hippocampal sclerosis associated with human temporal lobe epilepsy. Neurosci Lett 191:27-30. CrossRef Medline

Benarroch EE (2013) Microglia: multiple roles in surveillance, circuit shaping, and response to injury. Neurology 81:1079-1088. CrossRef Medline

Biber K, Owens T, Boddeke E (2014) What is microglia neurotoxicity (Not)? Glia 62:841-854. CrossRef Medline

Brotherstone R, Blackhall B, McLellan A (2010) Lengthening of corrected QT during epileptic seizures. Epilepsia 51:221-232. CrossRef Medline

Chan UPF, Lee JF, Wang SH, Leung KL, Chen GG (2003) Induction of colon cancer cell death by 7-hydroxystaurosporine (UCN-01) is associated with increased p38 MAPK and decreased Bcl-xL. Anticancer Drugs 14:761-766. Medline

Darbin O, Casebeer DJ, Naritoku DK (2002) Cardiac dysrhythmia associated with the immediate postictal state after maximal electroshock in freely moving rat. Epilepsia 43:336-341. CrossRef Medline

Delgado M, Munoz-Elias EJ, Gomariz RP, Ganea D (1999) Vasoactive intestinal peptide and pituitary adenylate cyclase-activating polypeptide enhance il-10 production by murine macrophages: in vitro and in vivo studies. J Immunol 162:1707-1716. Medline

Drage MG, Holmes GL, Seyfried TN (2002) Hippocampal neurons and glia in epileptic EL mice. J Neurocytol 31:681-692. CrossRef Medline

Farnham MMJ, Li Q, Goodchild AK, Pilowsky PM (2008) PACAP is expressed in sympathoexcitatory bulbospinal $\mathrm{C} 1$ neurons of the brain stem and increases sympathetic nerve activity in vivo. Am J Physiol 294: R1304-R1311. CrossRef Medline

Farnham MMJ, Inglott MA, Pilowsky PM (2011) Intrathecal PACAP-38 causes increases in sympathetic nerve activity and heart rate but not blood pressure in the spontaneously hypertensive rat. Am J Physiol 300:H214H222. CrossRef Medline

Farnham MM, Lung MS, Tallapragada VJ, Pilowsky PM (2012) PACAP causes PAC1/VPAC2 receptor mediated hypertension and sympathoex- citation in normal and hypertensive rats. Am J Physiol 303:H910-H917. CrossRef Medline

Ferrer I, Blanco R, Carmona M, Puig B, Domínguez I, Viñals F (2002) Active, phosphorylation-dependent MAP kinases, MAPK/ERK, SAPK/JNK and $\mathrm{p} 38$, and specific transcription factor substrates are differentially expressed following systemic administration of kainic acid to the adult rat. Acta Neuropathol 103:391-407. CrossRef Medline

Gordon PH, Moore DH, Miller RG, Florence JM, Verheijde JL, Doorish C, Hilton JF, Spitalny GM, MacArthur RB, Mitsumoto H, Neville HE, Boylan K, Mozaffar T, Belsh JM, Ravits J, Bedlack RS, Graves MC, McCluskey LF, Barohn RJ, Tandan R; Western ALS Study Group (2007) Efficacy of minocycline in patients with amyotrophic lateral sclerosis: a phase III randomised trial. Lancet Neurol 6:1045-1053. CrossRef Medline

Gottschall PE, Tatsuno I, Arimura A (1994) Regulation of interleukin-6 (IL-6) secretion in primary cultured rat astrocytes: Synergism of interleukin-1 (IL-1) and pituitary adenylate cyclase activating polypeptide (PACAP). Brain Res 637:197-203. CrossRef Medline

Hotta H, Koizumi K, Stewart M (2009) Cardiac sympathetic nerve activity during kainic acid-induced limbic cortical seizures in rats. Epilepsia 50: 923-927. CrossRef Medline

Hua XY, Svensson CI, Matsui T, Fitzsimmons B, Yaksh TL, Webb M (2005) Intrathecal minocycline attenuates peripheral inflammation-induced hyperalgesia by inhibiting p38 MAPK in spinal microglia. Eur J Neurosci 22:2431-2440. CrossRef Medline

Imai F, Suzuki H, Oda J, Ninomiya T, Ono K, Sano H, Sawada M (2007) Neuroprotective effect of exogenous microglia in global brain ischemia. J Cereb Blood Flow Met 27:488-500. CrossRef Medline

Jeon SH, Kim YS, Bae CD, Park JB (2000) Activation of JNK and p38 in rat hippocampus after kainic acid induced seizure. Exp Mol Med 32:227-230. CrossRef Medline

Kim WK, Ganea D, Jonakait GM (2002) Inhibition of microglial CD40 expression by pituitary adenylate cyclase-activating polypeptide is mediated by interleukin-10. J Neuroimmunol 126:16-24. CrossRef Medline

Kitamura Y, Takata K, Inden M, Tsuchiya D, Yanagisawa D, Nakata J, Taniguchi $\mathrm{T}$ (2004) Intracerebroventricular injection of microglia protects against focal brain ischemia. J Pharmacol Sci 94:203-206. CrossRef Medline

Kitamura Y, Yanagisawa D, Inden M, Takata K, Tsuchiya D, Kawasaki T, Taniguchi T, Shimohama S (2005) Recovery of focal brain ischemiainduced behavioral dysfunction by intracerebroventricular injection of microglia. J Pharmacol Sci 97:289-293. CrossRef Medline

Kreisel T, Frank MG, Licht T, Reshef R, Ben-Menachem-Zidon O, Baratta MV, Maier SF, Yirmiya R (2014) Dynamic microglial alterations underlie stress-induced depressive-like behavior and suppressed neurogenesis. Mol Psychiatry 19:699-709. CrossRef Medline

Lai AY, Todd KG (2008) Differential regulation of trophic and proinflammatory microglial effectors is dependent on severity of neuronal injury. Glia 56:259-270. CrossRef Medline

Lai CC, Wu SY, Lin HH, Dun NJ (1997) Excitatory action of pituitary adenylate cyclase activating polypeptide on rat sympathetic preganglionic neurons in vivo and in vitro. Brain Res 748:189-194. CrossRef Medline

Lalancette-Hébert M, Gowing G, Simard A, Weng YC, Kriz J (2007) Selective ablation of proliferating microglial cells exacerbates ischemic injury in the brain. J Neurosci 27:2596-2605. CrossRef Medline

Lévesque M, Avoli M (2013) The kainic acid model of temporal lobe epilepsy. Neurosci Biobehav Rev 37:2887-2899. CrossRef Medline

Li L, Lu J, Tay SS, Moochhala SM, He BP (2007) The function of microglia, either neuroprotection or neurotoxicity, is determined by the equilibrium among factors released from activated microglia in vitro. Brain Res 1159: 8-17. CrossRef Medline

Loane DJ, Byrnes KR (2010) Role of microglia in neurotrauma. Neurotherapeutics 7:366-377. CrossRef Medline

Luckhaus C, Hennersdorf M, Bell M, Agelink MW, Zielasek J, Cordes J (2008) Brugada syndrome as a potential cardiac risk factor during electroconvulsive therapy (ECT). World J Biol Psychiatry 9:150-153. CrossRef Medline

März P, Cheng JG, Gadient RA, Patterson PH, Stoyan T, Otten U, Rose-John S (1998) Sympathetic neurons can produce and respond to interleukin 6. Proc Natl Acad Sci U S A 95:3251-3256. CrossRef Medline

Mirrione MM, Konomos DK, Gravanis I, Dewey SL, Aguzzi A, Heppner FL, Tsirka SE (2010) Microglial ablation and lipopolysaccharide precondi- 
tioning affects pilocarpine-induced seizures in mice. Neurobiol Dis 39: 85-97. CrossRef Medline

Mokriski BK, Nagle SE, Papuchis GC, Cohen SM, Waxman GJ (1992) Electroconvulsive therapy-induced cardiac arrhythmias during anesthesia with methohexital, thiamylal, or thiopental sodium. J Clin Anesth 4:208212. CrossRef Medline

Mosser DM, Edwards JP (2008) Exploring the full spectrum of macrophage activation. Nat Rev Immunol 8:958-969. CrossRef Medline

Müngen B, Berilgen MS, Arikanoğlu A (2010) Autonomic nervous system functions in interictal and postictal periods of nonepileptic psychogenic seizures and its comparison with epileptic seizures. Seizure 19:269-273. CrossRef Medline

Neumann J, Sauerzweig S, Rönicke R, Gunzer F, Dinkel K, Ullrich O, Gunzer M, Reymann KG (2008) Microglia cells protect neurons by direct engulfment of invading neutrophil granulocytes: A new mechanism of CNS immune privilege. J Neurosci 28:5965-5975. CrossRef Medline

Nimmerjahn A, Kirchhoff F, Helmchen F (2005) Neuroscience: Resting microglial cells are highly dynamic surveillants of brain parenchyma in vivo. Science 308:1314-1318. CrossRef Medline

Nomura M, Ueta Y, Hannibal J, Serino R, Yamamoto Y, Shibuya I, Matsumoto T, Yamashita H (2000) Induction of pituitary adenylate cyclaseactivating polypeptide mRNA in the medial parvocellular part of the paraventricular nucleus of rats following kainic-acid-induced seizure. Neuroendocrinology 71:318-326. CrossRef Medline

Pansani AP, Colugnati DB, Schoorlemmer GH, Sonoda EY, Cavalheiro EA, Arida RM, Scorza FA, Cravo SL (2011) Repeated amygdala-kindled seizures induce ictal rebound tachycardia in rats. Epilepsy Behav 22:442449. CrossRef Medline

Peltola J, Palmio J, Korhonen L, Suhonen J, Miettinen A, Hurme M, Lindholm D, Keränen T (2000) Interleukin-6 and interleukin-1 receptor antagonist in cerebrospinal fluid from patients with recent tonic-clonic seizures. Epilepsy Res 41:205-211. CrossRef Medline

Penkowa M, Molinero A, Carrasco J, Hidalgo J (2001) Interleukin-6 deficiency reduces the brain inflammatory response and increases oxidative stress and neurodegeneration after kainic acid-induced seizures. Neuroscience 102:805-818. CrossRef Medline

Persson M, Rönnbäck L (2012) Microglial self-defence mediated through GLT-1 and glutathione. Amino Acids 42:207-219. CrossRef Medline

Reglodi D, Somogyvari-Vigh A, Vigh S, Kozicz T, Arimura A (2000) De- layed systemic administration of PACAP38 is neuroprotective in transient middle cerebral artery occlusion in the rat. Stroke 31:1411-1417. CrossRef Medline

Ringer C, Büning LS, Schäfer MK, Eiden LE, Weihe E, Schütz B (2013) PACAP signaling exerts opposing effects on neuroprotection and neuroinflammation during disease progression in the SOD1(G93A) mouse model of amyotrophic lateral sclerosis. Neurobiol Dis 54:32-42. CrossRef Medline

Sakamoto K, Saito T, Orman R, Koizumi K, Lazar J, Salciccioli L, Stewart M (2008) Autonomic consequences of kainic acid-induced limbic cortical seizures in rats: peripheral autonomic nerve activity, acute cardiovascular changes, and death. Epilepsia 49:982-996. CrossRef Medline

Sakon S, Xue X, Takekawa M, Sasazuki T, Okazaki T, Kojima Y, Piao JH, Yagita H, Okumura K, Doi T, Nakano H (2003) NF- $\kappa$ B inhibits TNFinduced accumulation of ROS that mediate prolonged MAPK activation and necrotic cell death. EMBO J 22:3898-3909. CrossRef Medline

Schreihofer AM, Guyenet PG (1997) Identification of C1 presympathetic neurons in rat rostral ventrolateral medulla by juxtacellular labeling in vivo. J Comp Neurol 387:524-536. CrossRef Medline

Shapiro LA, Wang L, Ribak CE (2008) Rapid astrocyte and microglial activation following pilocarpine-induced seizures in rats. Epilepsia 49:33-41. CrossRef Medline

Shioda S, Ozawa H, Dohi K, Mizushima H, Matsumoto K, Nakajo S, Takaki A, Zhou CJ, Nakai Y, Arimura A (1998) PACAP protects hippocampal neurons against apoptosis: Involvement of JNK/SAPK signaling pathway. Ann NY Acad Sci 865:111-117. CrossRef Medline

Shioda S, Ohtaki H, Nakamachi T, Dohi K, Watanabe J, Nakajo S, Arata S, Kitamura S, Okuda H, Takenoya F, Kitamura Y (2006) Pleiotropic functions of PACAP in the CNS: Neuroprotection and neurodevelopment. Ann NY Acad Sci 1070:550-560. CrossRef Medline

Tolstykh GP, Cavazos JE (2013) Potential mechanisms of sudden unexpected death in epilepsy. Epilepsy Behav 26:410-414. CrossRef Medline

Vinet J, Weering HR, Heinrich A, Kälin RE, Wegner A, Brouwer N, Heppner FL, Rooijen Nv, Boddeke HW, Biber K (2012) Neuroprotective function for ramified microglia in hippocampal excitotoxicity. J Neuroinflammation 9:27. CrossRef Medline

Wannamaker BB (1985) Autonomic nervous system and epilepsy. Epilepsia 26:S31-S39. CrossRef Medline 